\title{
OBJETOS DE APRENDIZAGEM PARA O ENSINO DE SEQUENCIAS REPETITIVAS E RECURSIVAS NOS ANOS INICIAIS
}

\author{
LEARNING OBJECTS FOR TEACHING REPETITIVE AND RECURSIVE SEQUENCES IN THE \\ EARLY GRADES
}

\author{
Italândia Ferreira de Azevedo ${ }^{1}$ \\ Renata Teófilo de Sousa ${ }^{2}$ \\ Monaliza de Azevedo Silva ${ }^{3}$ \\ Francisco Régis Vieira Alves ${ }^{4}$
}

RESUMO: O presente trabalho apresenta uma proposta didática para o ensino de Sequências Numéricas nos anos iniciais do Ensino Fundamental, com uso de Objetos de Aprendizagem (OAs). O objetivo é apresentar a utilização de dois Objetos de Aprendizagem que abordam conceitos de sequências repetitivas e recursivas, como forma de auxiliar o planejamento do professor de Matemática dos anos iniciais. A metodologia deste trabalho teve uma abordagem qualitativa do tipo exploratória, em que se realizou um mapeamento de alguns Objetos de Aprendizagem do repositório Mídias Digitais para a Matemática (MDMat) da Universidade Federal do Rio Grande do Sul (UFRGS), devido ao seu livre acesso pela comunidade acadêmica, bem como sua possibilidade de reprodução por outros pesquisadores e professores da Educação Básica. Este repositório apresenta OAs com grande potencial para alavancar o pensamento algébrico dos alunos por meio do desenvolvimento de seu raciocínio lógico e geométrico. Espera-se contribuir com o planejamento docente no que concerne à construção de uma aprendizagem efetiva por meio da implementação de tecnologias digitais no Ensino de Matemática. Pretende-se, a posteriori, investigar outros tipos de OAs e realizar uma formação voltada para professores dos anos iniciais do Ensino Fundamental na cidade de Fortaleza - CE, buscando validar tais recursos como proposta didática.

\footnotetext{
Mestra em Ensino de Matemática pelo Instituto Federal de Ciência e Tecnologia do Estado do Ceará (IFCE). Professora da rede estadual de ensino do Ceará - EEEP Joaquim Moreira de Sousa. ORCID: https://orcid.org/oooo-oooz$4684-5397$.

${ }^{2}$ Mestranda em Ensino de Ciências e Matemática - IFCE campus Fortaleza. Especialista em Ensino de Matemática UVA, Qualificação em Ensino de Matemática no Estado do Ceará - UFC. Pós-graduada em Didática e Metodologias Ativas na aprendizagem e MBA em Gestão Escolar - UniAmérica. Professora da Secretaria de Educação Básica do Estado do Ceará - EEEP Professora Lysia Pimentel Gomes Sampaio Sales. Instituto Federal de Ciência e Tecnologia do Estado do Ceará. ORCID: https://orcid.org/oooo-ooor-5507-2691.

${ }^{3}$ Graduanda em Pedagogia. Universidade Estadual Vale do Acaraú - UVA.

${ }^{4}$ Doutor em Educação pela Universidade Federal do Ceará, Bolsista de produtividade do CNPQ - PQ2. Professor permanente do Programa de Pós-Graduação em Ensino de Ciências e Matemática do IFCE, Professor permanente do Programa de Pós-Graduação em Ensino de Ciências e Matemática da Universidade Federal do Ceará. Professor permanente do Programa de Pós-Graduação do Mestrado Profissional em Educação Profissional Tecnológica. Professor titular do IFCE - departamento de Matemática e Física. Instituto Federal de Ciência e Tecnologia do Estado do Ceará. Líder do Grupo de Pesquisa CNPQ Ensino de Ciências e Matemática. Coordenador acadêmico do Doutorado em rede RENOEN, polo IFCE. Página pessoal: https://ifce.academia.edu/RegisFrancisco/Journal-Articles. Endereço para correspondência: Avenida Treze de Maio, 2081, 60040-215, Fortaleza, Ceará, Brasil. E-mail: fregis@ifce.edu.br. ORCID: http://orcid.org/oooo-ooo3-3710-156.
} 
Palavras-chave: Objetos de aprendizagem. Sequências repetitivas e recursivas. Ensino de matemática.

ABSTRACT: The present work presents a didactic proposal for the teaching of Numerical Sequences in the early years of Elementary School, using Learning Objects (OAs). The objective is to present the use of two Learning Objects that approach concepts of repetitive and recursive sequences, as a way to assist the planning of the mathematics teacher in the early years. The methodology of this work had a qualitative approach of the exploratory type, in which a mapping of some Learning Objects of the repository Digital Media for Mathematics (MDMat) of the Federal University of Rio Grande do Sul (UFRGS) was carried out, due to its free access by the academic community, as well as its possibility of reproduction by other researchers and teachers of Basic Education. This repository presents OAs with great potential to leverage students' algebraic thinking through the development of their logical and geometric reasoning. It is expected to contribute to teaching planning with regard to the construction of effective learning through the implementation of digital technologies in Mathematics Education. It is intended, posteriori, to investigate other types of OAs and carry out training aimed at teachers of the early years of Elementary School in the city of Fortaleza - CE, seeking to validate such resources as a didactic proposal.

Keywords: Learning objects. Repetitive and recursive sequences. Mathematics teaching.

\section{INTRODUÇÃO}

Em virtude da crise sanitária provocada pela pandemia da COVID-I9, muitos países adotaram medidas de distanciamento físico e construíram uma nova rotina, como o home office e a suspensão das aulas presenciais nos espaços escolares (SANTANA; SALES, 2020). Assim, o ensino passou a ser remoto e o uso das Tecnologias Digitais de Informação e Comunicação (TDICs) teve ampla disseminação e notoriedade, bem como reconhecimento de sua importância pela comunidade como um todo.

As TDICs possibilitaram o acesso à diversos recursos digitais e a continuidade das atividades pedagógicas, tornando possível o andamento do ano letivo. Segundo Ramos (202I) existe um diálogo gradual entre a esfera física e a digital, onde as informações são compartilhadas durante a realização de atividades de pesquisa, o que têm impactado profundamente a educação escolar e as formas de ensino e aprendizado que estamos habituados. Alguns destes recursos são plataformas como o YouTube, redes sociais, aplicativos de celular e as ferramentas G Suite for education (Google Meet, Google Classroom, Google Forms, etc.) que, antes deste cenário, não eram tão difundidas para fins pedagógicos, mas que se tornaram indispensáveis.

A partir do exposto, voltamos nosso olhar para a aprendizagem do aluno nesse novo contexto, principalmente no que tange ao Ensino de Matemática nos anos iniciais do Ensino Fundamental, sendo este um período de grande importância para a construção do pensamento lógico, algébrico e geométrico. Com isso, percebe-se a necessidade de trabalhar esta área do conhecimento de forma ativa, buscando construir significado para o aluno, com aplicações visíveis na resolução de problemas do cotidiano. 
Diante disso, surgem os questionamentos: Como despertar o interesse dos alunos na disciplina de Matemática? Como o docente de Matemática pode trabalhar sequências recursivas e repetitivas, de modo a desenvolver o pensamento algébrico de uma criança a partir de recursos digitais?

Para responder tais perguntas utilizaremos como base Objetos de Aprendizagem (OAs) para o ensino de sequências repetitivas e recursivas, buscando uma abordagem em que o aluno participe ativamente do processo de aprendizagem, tornando-se protagonista na construção do seu conhecimento.

Os OAs se apresentam "como uma vantajosa ferramenta de aprendizagem e instrução, a qual pode ser utilizada para o ensino de diversos conteúdos e revisão de conceitos" (AGUIAR; FLORES, 20I4, p. I2). Tais objetos podem ser utilizados para introduzir um assunto, praticar conceitos ou servir como proposta de atividade complementar. Para Carneiro e Silveira (2014), um OA precisa funcionar como um elemento facilitador do processo de ensino e de aprendizagem, o que corrobora com os objetivos deste trabalho.

Trazemos como objetivo uma proposta didática com o uso de dois Objetos de Aprendizagem que abordam este assunto para os anos iniciais como forma de auxiliar o planejamento do professor. Adotou-se como percurso metodológico uma abordagem qualitativa do tipo exploratória. Neste trabalho, os OAs têm como cerne aplicações voltadas para o ensino de sequências repetitivas e recursivas, por ser um assunto presente desde os anos iniciais do Ensino Fundamental, estendendo-se até o final da Educação Básica, com grande relevância para a construção do pensamento algébrico do aluno.

A intenção em mapear estes Objetos de Aprendizagem é propagar o conhecimento desses recursos como alternativa para a prática pedagógica de professores que ensinam matemática nos anos iniciais, trazendo a possibilidade de tornar o ensino de sequências mais dinâmico e atrativo ao estudante. Muitos alunos têm dificuldades na compreensão da Matemática e o uso de tecnologia pode despertar seu interesse e curiosidade, além de abrir caminhos para que estes possam ser agentes ativos do seu conhecimento.

\section{O ENSINO DE SEQUÊNCIAS NUMÉRICAS}

O pensamento algébrico tem despertado grande interesse e visibilidade nos últimos tempos, provavelmente pelo fato de a Álgebra estar entre as cinco unidades temáticas da Matemática a serem trabalhadas com alunos dos anos iniciais do Ensino Fundamental, presentes na Base Nacional Comum Curricular (BNCC), tendo grande relevância para a evolução do aluno nas séries subsequentes.

De acordo com Jungbluth, Silveira e Grando (2019, p. 97), "a unidade temática Álgebra tem como finalidade desenvolver o pensamento algébrico das crianças, e essa novidade cria novas demandas para os professores que atuam nesse nível de ensino". Assim, percebe-se a necessidade de os professores dos anos iniciais estarem familiarizados com essa temática.

Jungbluth, Silveira e Grando (2019) enfatizam em seu trabalho a construção do pensamento algébrico e sua relação com a generalização de padrões em sequências repetitivas e recursivas. Estes temas estão presentes na BNCC (2018) para os anos iniciais: 


\begin{abstract}
Nessa perspectiva, é imprescindível que algumas dimensões do trabalho com a álgebra estejam presentes nos processos de ensino e aprendizagem desde o Ensino Fundamental - Anos Iniciais, como as ideias de regularidade, generalização de padrões e propriedades da igualdade. No entanto, nessa fase, não se propõe o uso de letras para expressar regularidades, por mais simples que sejam. A relação dessa unidade temática com a de Números é bastante evidente no trabalho com sequências (recursivas e repetitivas), seja na ação de completar uma sequência com elementos ausentes, seja na construção de sequências segundo uma determinada regra de formação (BRASIL, 20I8, p. 270-27I).
\end{abstract}

Esses padrões podem ser relacionados com vários exemplos presentes na natureza e no cotidiano dos alunos, como disposição das folhas no caule de algumas plantas, nos espirais da pinha e no girassol. É possível encontrá-los também em estampas de tecidos, em notas musicais, em ladrilhos, entre outras situações.

Conforme o estudo e a análise da BNCC sobre as habilidades que envolvem o ensino de sequências e padrões, entende-se que, para abordar o conteúdo de sequências com o aluno, nessa fase de ensino, o professor deve se utilizar de estratégias que explorem material concreto ou digital, que proporcionem o desenvolvimento do pensamento algébrico, ampliando a visualização, identificação e compreensão de padrões e regra de formação, pois, segundo Oliveira (2019, p. 7), "a tecnologia digital pode ser ferramenta de ensino por ter como sua característica um padrão lógico de uma sequência".

A descrição de padrões implica na observação e compreensão de sequências, sendo estas numéricas ou geométricas, de modo a identificar suas regularidades e, por fim, expressá-las. Uma sequência é dita repetitiva quando tem um mesmo padrão de organização que se repete a cada elemento, sendo consideradas por Ponte, Branco e Matos (2009, p. 47) como sendo "as mais simples" e as que "podem ser usadas para o trabalho inicial da procura de regularidades e da generalização". Por exemplo, na sequência 2, 4, 6, $8, \ldots$, o padrão de repetição é dado pela soma do valor 2 a cada termo subsequente, ou seja, cada termo a partir do segundo, é igual ao anterior acrescido do valor 2 na composição do novo termo, o que nos remete a uma abordagem inicial referente às Progressões Aritméticas, estudadas no Ensino Médio.

Com relação às sequências recursivas, estas explicitam seu primeiro valor (ou primeiros valores) e definem outros valores na sequência em termos dos valores iniciais segundo uma regra. Estas sequências podem ser crescentes, decrescentes, lineares ou não lineares, ou seja, sua tradução algébrica pode ser feita ou não a partir de uma expressão polinomial do I. ograu (BARBOSA et al., 20II). Tais sequências são de grande importância na passagem da Aritmética para a Álgebra. Um exemplo é a Sequência de Fibonacci ${ }^{5}$ que traz os termos I, I, 2, 3, 5, 8, I3, e sua recursividade está no fato de, a partir do segundo termo, os subsequentes são obtidos por meio da soma dos dois termos anteriores: $2=\mathrm{I}+\mathrm{I} ; 3$ $=\mathrm{I}+2 ; 5=2+3$ e assim por diante.

Azevedo, Silva e Alves (2020) enfatizam a importância de se trabalhar o ensino de sequências e padrões ainda nos anos iniciais, pois nesta etapa escolar os alunos estão desenvolvendo sua cognição matemática. Ou seja, à medida que aprendem um assunto

\footnotetext{
${ }^{5}$ É uma sucessão de números que, misteriosamente, aparece em muitos fenômenos da natureza. Descrita no final do século 12 pelo italiano Leonardo Fibonacci, ela é infinita e começa com i e i. Os números seguintes são sempre a soma dos dois números anteriores. Portanto, depois de I e I, vêm 2, 3, 5, 8, I3, 21, 34...
} 
novo dentro do campo da Matemática, concebem seu pensamento lógico, algébrico e geométrico.

Partindo de tais premissas, percebe-se a importância do trabalho voltado para o ensino de sequências nas séries iniciais, como forma de desenvolver o raciocínio do aluno, visando sua evolução para séries subsequentes. Na próxima seção abordaremos os Objetos de Aprendizagem, cerne deste trabalho, que tem potencial para contribuir para que esta evolução ocorra.

\section{OBJETOS DE APRENDIZAGEM}

Com o advento das TDICs houve aceleração exponencial no que tange à necessidade de desenvolvimento do processo de ensino e aprendizagem de Matemática, bem como a elaboração de materiais didáticos, com uso de sons, cores e movimentos, buscando estreitar os laços e proporcionar uma melhor experiência e interatividade com os usuários (SCOLARI; BERNARDI; CORDENONSI, 2007).

Entretanto, de acordo com Costa et al. (2020, apud VALENTE, 2006) o uso de recursos tecnológicos não é algo novo no campo educacional e, para surtir efeito positivo, deve ser bem planejado e organizado. Caso não haja um planejamento adequado, o uso destes recursos pode caracterizar apenas a informatização do espaço educativo e demonstrar pouca efetividade na potencialização de uma aprendizagem mais significativa para o educando. Ramos (2021) reitera que o professor tem papel fundamental na mediação da aquisição do conhecimento por meio de ferramentas tecnológicas, sendo imprescindível que o docente esteja preparado para utilizá-la de modo a cooperar para que o processo de ensino e aprendizagem ocorra de forma satisfatória.

Com isso, um recurso importante que têm ganhado espaço em práticas metodológicas são os Objetos de Aprendizagem (OAs), sendo utilizados como ferramenta de apoio para docentes de diversas áreas, sendo meios facilitadores da aprendizagem. Azevedo, Silva e Alves (2020) comentam que os OAs tem potencial para ofertar uma contribuição positiva para o ensino de sequências, estimulando a aprendizagem do aluno de forma ativa, além de instigar a curiosidade e tornar o momento da de Matemática aula divertido e prazeroso.

Objetos de Aprendizagem (OAs) são recursos digitais utilizados para apoiar a aprendizagem de um determinado assunto. Neste trabalho, em particular, utilizaremos OAs para o ensino de sequências recursivas e repetitivas, verificando sua viabilidade para aplicação em séries iniciais do Ensino Fundamental. Desta forma, Castro Filho (2007) define Objetos de Aprendizagem como:

Objetos de aprendizagem, doravante denominados de OA, é um termo surgido no início do século XXI para indicar recursos digitais (vídeo, animação, simulação, etc.) os quais permitem que professores e alunos explorem conceitos específicos em matemática, ciências, linguagem etc. (CASTRO FILHO, 2007, p. 2).

Estes objetos podem ser criados em diversas mídias e formatos, desde que sejam pensados metodologicamente para alcançar um objetivo dentro da proposta de aprendizagem do conteúdo selecionado. Para Aguiar e Flôres (2014) ao serem manipulados em um contexto educacional, tendo como cerne o conhecimento, o OA serve para mediar e facilitar a formação e consolidação de novos saberes. 
Além disso, durante esse cenário da pandemia do Novo Coronavírus tem sido importante uma ressignificação e reestruturação da práxis docente. Para tal, o uso da tecnologia e das ferramentas digitais tem se configurado em recursos imprescindíveis para o andamento das atividades escolares e para a readaptação do processo de ensino e aprendizagem. Nesse sentido, Hanauer (2020) enfatiza a importância de se desenvolver o trabalho lúdico utilizando esses recursos tecnológicos, como o Google Meet e aplicativos de Chat online, em que o aluno se sente motivado em se engajar, diante da presença dos demais colegas e professores. Segundo a autora:

Pode-se desenvolver chamadas, e algumas dinâmicas como responder os questionamentos e melhorar o desempenho dos estudantes ao realizar as tarefas propostas no WhatsApp e Google sala de aula. A metodologia aplicada através das aulas remotas teve como incentivo ao estudo e superou obstáculos em que o professor estando distante fisicamente do aluno, percebe-se que os objetivos foram alcançados (HANAUER, 2020, p. 165).

Em um arremate para esta seção, Cazella et al. (20II) aponta que a possibilidade de uso de diferentes mídias digitais permite que os OAs tenham sua utilização difundida, atingindo especialmente os professores de Educação Básica, que têm nos objetos um recurso importante para suporte ao trabalho pedagógico. Deste modo, os OAs no ensino de Matemática podem auxiliar o aluno em seu processo de aprendizagem em etapas como relação entre conceitos prévios e novos, análise de hipóteses, relações entre o conteúdo e suas respectivas aplicações, entre outros benefícios.

\section{METODOLOGIA}

Esta pesquisa utilizou-se da abordagem qualitativa do tipo exploratória, dado que, conforme Gil (2002, p. 4I), “[...] estas pesquisas têm como objetivo principal o aprimoramento de ideias ou a descoberta de intuições. Seu planejamento é, portanto, bastante flexível, de modo que possibilite a consideração dos mais variados aspectos relativos ao fato estudado".

Neste trabalho, foi realizada a análise de um conjunto de Objetos de Aprendizagem sobre o conteúdo de sequências repetitivas e recursivas do repositório do grupo Mídias Digitais para a Matemática ${ }^{6}$ (MDMat), devido ao seu livre acesso pela comunidade acadêmica, bem como sua possibilidade de reprodução por outros pesquisadores e/ou professores da Educação Básica.

Dentre as características analisadas, priorizou-se os OAs que atendessem o objetivo desta pesquisa e que fossem de uso funcional, pois buscou-se recursos voltados para os anos iniciais do Ensino Fundamental, com abordagem conceitual de sequências de forma prática.

No Quadro I estão expostos Objetos de Aprendizagem que abordam o tema em estudo. Neste caso, separamos de forma clara os que exploram sequências repetitivas dos que abordam sequências recursivas. Disponibilizamos também seu endereço eletrônico para facilitar o acesso do professor.

\footnotetext{
${ }^{6} \mathrm{O}$ MDMat é um repositório da Universidade Federal do Rio Grande do Sul (UFRGS) que contém mídias digitais para o ensino-aprendizagem de matemática, contendo Objetos de Aprendizagem voltados para o auxílio do professor em sala de aula.
} 
Quadro I - Descrição dos OAs presentes no repositório MDMat

\begin{tabular}{|c|c|c|c|c|}
\hline $\mathrm{OA}$ & Série & Descrição & Sequência & Disponível em \\
\hline $\begin{array}{l}\text { Sequências } \\
\text { com } \\
\text { formas } \\
\text { geométrica } \\
\text { s }\end{array}$ & $4^{\circ}$ e $5^{\circ} \mathrm{EF}$ & $\begin{array}{l}\text { O aluno deve analisar a sequência } \\
\text { apresentada, identificando qual figura } \\
\text { está faltando e completá-la. Para isso, } \\
\text { deverá verificar entre as opções de } \\
\text { figuras e, com o auxílio do mouse, } \\
\text { arrastá-la até o local indicado. }\end{array}$ & Recursiva & $\begin{array}{l}\text { http://mdmat.m } \\
\text { at.ufrgs.br/anos_i } \\
\text { niciais/objetos/se } \\
\text { quencias_formas. } \\
\text { htm }\end{array}$ \\
\hline $\begin{array}{l}\text { Giramund } \\
\text { o }\end{array}$ & $\begin{array}{l}\mathrm{I}^{\mathrm{o}} \text { até } 4^{\mathrm{o}} \\
\mathrm{EF}\end{array}$ & $\begin{array}{l}\text { O aluno deve analisar a sequência } \\
\text { apresentada e descobrir a figura que } \\
\text { falta. Para completar a sequência, } \\
\text { deve clicar em "Girar" e segurar o } \\
\text { clique até que a figura fique na } \\
\text { posição desejada. Em seguida, arrastá- } \\
\text { la até o local indicado. }\end{array}$ & $\begin{array}{l}\text { Repetitiv } \\
\text { a }\end{array}$ & $\begin{array}{l}\text { http://mdmat.m } \\
\text { at.ufrgs.br/anos_i } \\
\text { niciais/objetos/gi } \\
\text { ramundo.htm }\end{array}$ \\
\hline $\begin{array}{l}\text { Sequência } \\
\text { de } \\
\text { cubinhos }\end{array}$ & $4^{\circ}$ e $5^{\circ} \mathrm{EF}$ & $\begin{array}{l}\text { O objetivo deste OA é descobrir qual } \\
\text { a composição de cubos que completa a } \\
\text { próxima figura, de acordo com a } \\
\text { sequência mostrada inicialmente. }\end{array}$ & Recursiva & $\begin{array}{l}\text { http://mdmat.m } \\
\text { at.ufrgs.br/anos_i } \\
\text { niciais/objetos/se } \\
\text { quencias_cubinho } \\
\text { s.htm }\end{array}$ \\
\hline $\begin{array}{l}\text { Ordem dos } \\
\text { fatos }\end{array}$ & Iㅇ e $2^{-} \mathrm{o} E$ & $\begin{array}{l}\text { É preciso colocar os quadrinhos na } \\
\text { ordem em que acontecem os fatos, } \\
\text { usando o mouse, e arrastando cada } \\
\text { uma das imagens para uma das } \\
\text { posições indicadas. }\end{array}$ & Recursiva & $\begin{array}{l}\text { http://mdmat.m } \\
\text { at.ufrgs.br/anos_i } \\
\text { niciais/objetos/se } \\
\text { quencias_carrinh } \\
\text { os.htm }\end{array}$ \\
\hline $\begin{array}{l}\text { Padrão de } \\
\text { construção }\end{array}$ & $4^{\circ}$ e $5^{\circ} \mathrm{EF}$ & $\begin{array}{l}\text { Faltam peças do muro. Há um padrão } \\
\text { em cada muro e para completar a } \\
\text { construção é necessário digitar o } \\
\text { número de peças coloridas que a } \\
\text { completa. Para mover uma peça, } \\
\text { clique sobre ela, arraste com o cursor } \\
\text { até o local desejado e solte-a. }\end{array}$ & Recursiva & $\begin{array}{l}\text { http://mdmat.m } \\
\text { at.ufrgs.br/anos_i } \\
\text { niciais/objetos/c } \\
\text { onst_muro.htm }\end{array}$ \\
\hline $\begin{array}{l}\text { Construção } \\
\text { de } \\
\text { mosaicos }\end{array}$ & $4^{\circ}$ e $5^{\circ} \mathrm{EF}$ & $\begin{array}{l}\text { O objetivo é preencher um tipo de } \\
\text { plano, como chãos e paredes, com os } \\
\text { ladrilhos. Para construir um mosaico, } \\
\text { clique nas setinhas que aparecem bem } \\
\text { abaixo no objeto e siga as instruções. }\end{array}$ & Recursiva & $\begin{array}{l}\text { http://mdmat.m } \\
\text { at.ufrgs.br/anos_i } \\
\text { niciais/objetos } / \mathrm{m} \\
\text { osaicos.htm }\end{array}$ \\
\hline
\end{tabular}

Fonte: Repositório MDMat.

Este repositório apresenta OAs com grande potencial para alavancar o pensamento algébrico dos alunos por meio do desenvolvimento de seu raciocínio lógico e geométrico. Entretanto, para este trabalho, selecionamos dois dentre estes OAs que são: "Sequência com formas geométricas" e "Sequência de cubinhos", como forma de desenvolver tais 
habilidades algébricas, lógicas e geométricas. Contudo pretende-se, a posteriori, investigar outros tipos de OAs e realizar uma formação voltada para professores dos anos iniciais do Ensino Fundamental na cidade de Fortaleza - CE, buscando validar tais recursos como proposta didática.

\section{EXPLORANDO OBJETOS DE APRENDIZAGEM PARA O ENSINO DE SEQUÊNCIAS}

A descrição dos Objetos de Aprendizagem a seguir tem como intenção ilustrar uma exploração didática utilizando tecnologias no Ensino de Matemática com foco no ensino de sequências repetitivas e recursivas, buscando a construção do pensamento algébrico de forma ativa e significativa para os alunos. Ademais, os objetos selecionados podem também configurar-se como recurso possível de ser utilizado no planejamento dos professores para o ensino remoto.

\section{I Sequência com formas geométricas}

Este jogo explora conceitos de sequências repetitivas. Inicia-se com padrões de figuras simples e, no decorrer das etapas aumenta o nível de raciocínio. Assim, este Objeto de aprendizagem exige como conhecimento prévio dos alunos a identificação da regularidade entre figuras geométricas a partir de um certo padrão, abordando, uma habilidade explorada na BNCC (Brasil, 2018, p. 283), pertinente ao $2^{\circ}$ ano do EF, "descrever os elementos ausentes em sequências repetitivas e em sequências recursivas de números naturais, objetos ou figuras".

Neste jogo, o aluno precisa seguir a ordem da sequência, acrescentando, no último quadrado, a peça que está faltando. Veja, na Figura I, dois exemplos de sequências que podem surgir.

\section{Figura I - Exemplos de sequências}
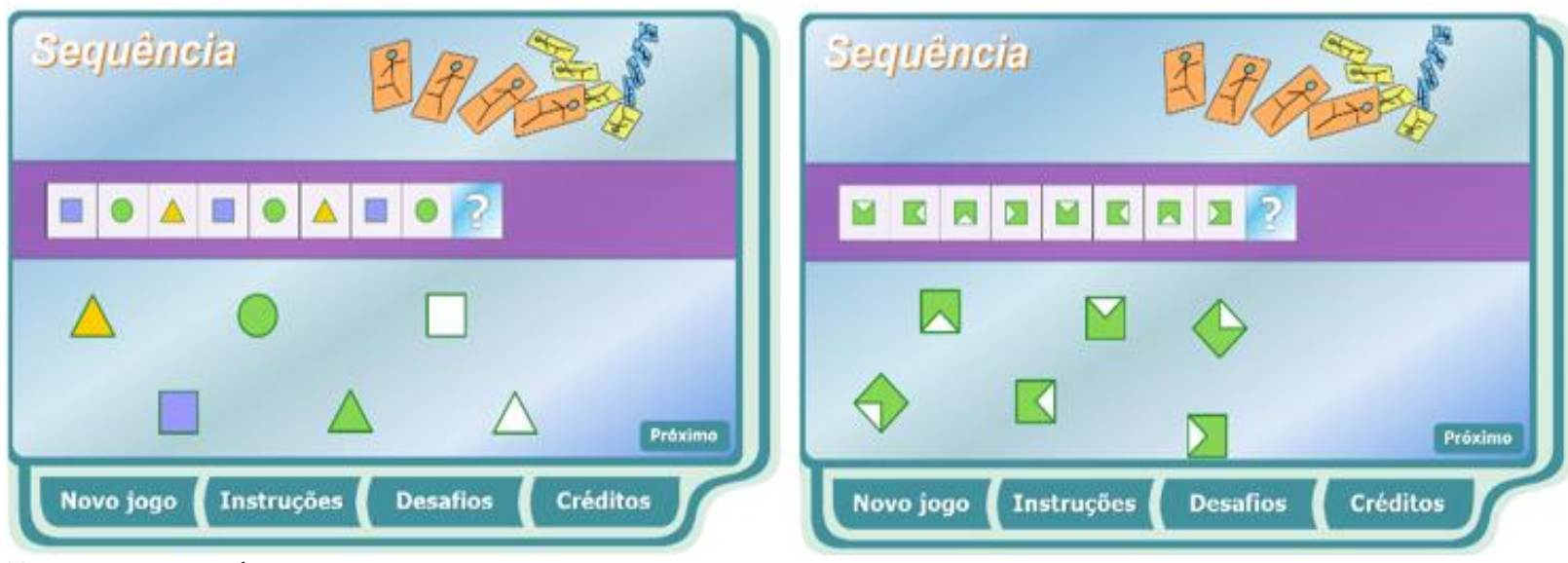

Fonte: Registro dos autores.

Observe que na Figura I, mesmo sendo uma sequência de figuras, existe um nível de dificuldade. Ou seja, na figura à esquerda é solicitado apenas que o aluno observe a 
forma geométrica e sua cor. Entretanto, na sequência à direita, o aluno precisa explorar outras habilidades como identificar o padrão e a posição do triângulo branco dentro do quadrado verde. Veja na Figura 2 outros exemplos de sequências repetitivas abordadas neste OA.

Figura 2 - Sequências repetitivas maior nível de complexidade
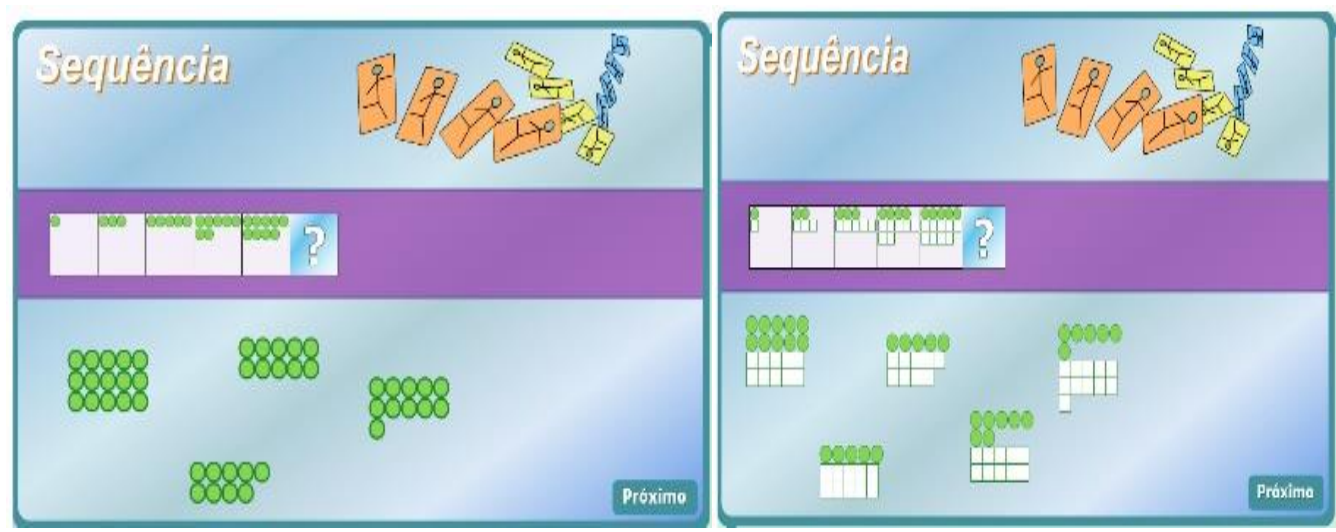

Fonte: Registro dos autores.

Observe que nestes exemplos, cada sequência explora o raciocínio do aluno de forma gradual. Scolari, Bernardi e Cordenonsi (2007) corroboram com isto ao trazerem que o estágio operatório formal no desenvolvimento da criança promove o desenvolvimento de seu pensamento como o de um adulto, iniciando o pensamento com ideias abstratas e evoluindo em seu raciocínio lógico. Por fim, esse OA apresenta, de forma bem simples, a pontuação para cada jogada, como mostra a Figura 3.

Figura 3 - Pontuação acumulada

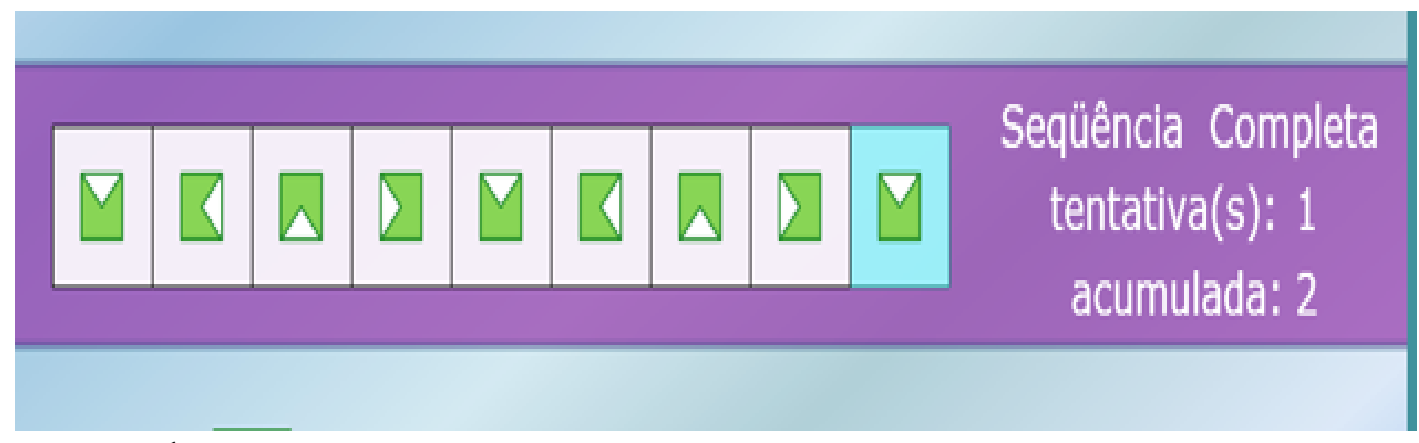

Fonte: Registro dos autores.

\subsection{Sequência de cubinhos}

Este jogo tem um cenário no formato $3 \mathrm{D}$, trazendo como objetivo descobrir a composição de cubos que faltam para completar a sequência, observando as composições apresentadas. Na Figura 4, traz-se a tela inicial deste jogo. 
Figura 4 - Tela inicial do jogo 'sequências de cubinhos'

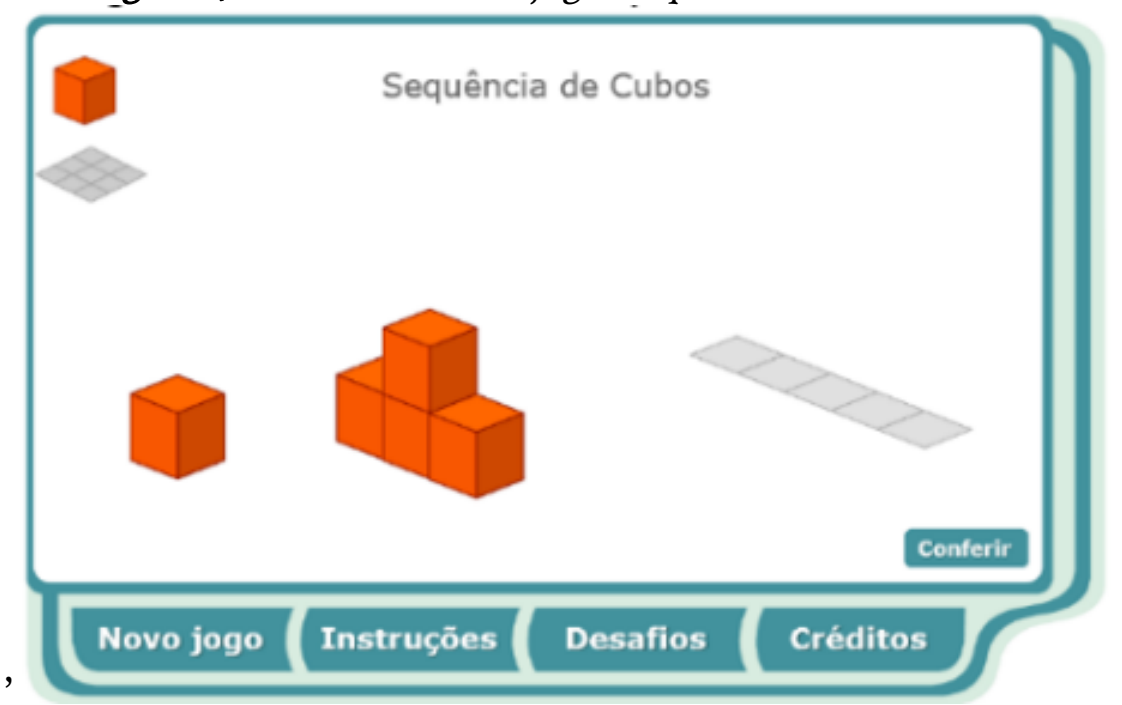

Fonte: Registro dos autores.

O interessante desse OA é que ele explora conhecimentos algébricos no intuito de provocar o aluno a pensar, explorando habilidades que vão além das apresentadas nos OAs anteriores. Para Boucherville e Viana (2019, p. 42), essas "situações com que os alunos se deparam e tentam torná-la parte de seu conhecimento são executadas de diferentes formas, podendo se demonstrar de diversas maneiras e complexidades, e, portanto, levar a diferentes e boas estratégias". Aqui, o aluno pode resolver a sequência movimentando cubo por cubo, de forma aleatória, até complementar a composição proposta. No entanto, similarmente, o aluno pode formular uma expressão para resolver a sequência, identificando a quantidade de cubos que serão necessários. Contudo, para que um aluno dos anos iniciais tenha a habilidade de "montar uma fórmula", faz-se necessário um trabalho bem elaborado pelo professor. Veja, na Figura 5, um exemplo de aplicação com seu passo a passo.

Figura 5 - Exemplo de aplicação
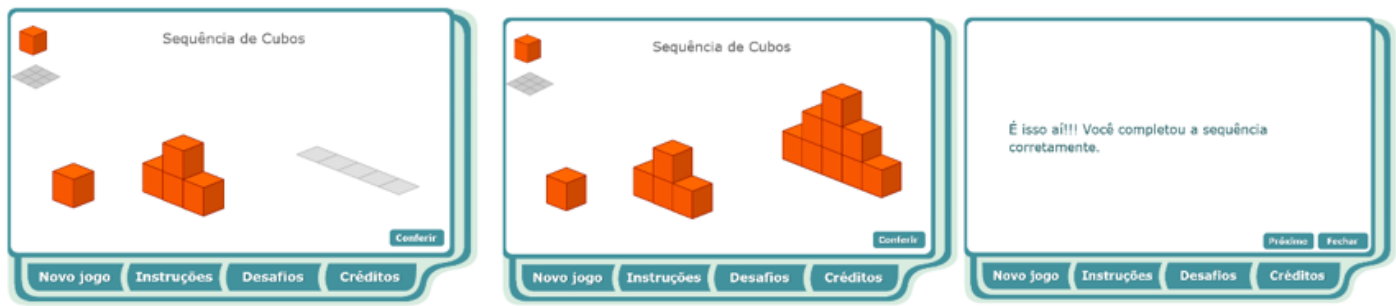

Fonte: Registro dos autores. 
Uma formulação possível de surgir seria a identificação de uma sequência com um padrão a partir da soma dos números naturais ímpares, como mostra a Figura 6.

Figura 6 - Formulação da sequência

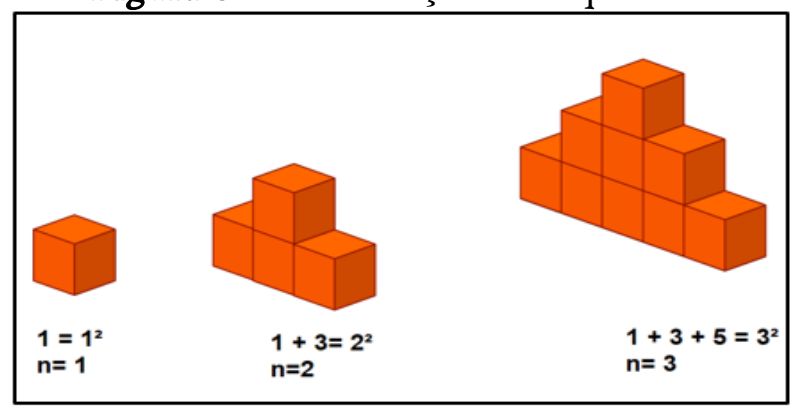

Fonte: Registro dos autores

Então, a partir da descoberta do padrão da sequência, os alunos serão capazes de descobrir a quantidade de cubos necessários para qualquer figura que envolve essa sequência: $(\mathrm{I}, 4,9, \ldots)$, percebendo a recursividade presente na soma dos números naturais ímpares ou, caso os alunos estejam em etapas finais do Ensino Fundamental, eles podem perceber que a sequência se trata do quadrado dos números naturais $\mathrm{I}^{2}, 2^{2}, 3^{2}, \ldots, \mathrm{n}^{2}$, e assim sucessivamente.

\section{CONSIDERAÇÕES FINAIS}

Os Objetos de Aprendizagem apontados neste trabalho trazem uma possibilidade de experiência dinâmica para a construção do conhecimento acerca de sequências recursivas e repetitivas de forma visual, buscando desenvolver o raciocínio dedutivo do estudante dos anos iniciais do Ensino Fundamental. Além disso, configura-se como uma metodologia ativa suporte ao docente que ensina matemática, apropriada para despertar o interesse de seus alunos, ao implementar uma atividade dinâmica e criativa por meio de tecnologias digitais no ensino de Matemática, sendo possível de ser aplicada de forma remota como um recurso extra ao professor neste cenário atual da educação.

O objetivo deste trabalho foi alcançado, pois os Objetos de Aprendizagem escolhidos, abordando a temática de sequências, foram investigados, analisados e descritos, permitindo-nos concluir que este recurso tem potencial para envolver o aluno na disciplina de Matemática, despertando seu interesse e desenvolvendo habilidades de raciocínio lógico, requisitos para as próximas etapas escolares.

No repositório investigado foram encontrados seis objetos de aprendizagem que exploram a temática investigada, caracterizando-se como uma fonte valiosa de informações para auxiliar o planejamento docente.

Entretanto, somente apresentar essas tecnologias digitais não é suficiente para garantir o aprendizado dos alunos. $O$ professor precisa incentivar a busca da aprendizagem, provocar curiosidade e estimular o estudo da Matemática. Para tal, pretende-se ampliar esta pesquisa envolvendo professores que ensinam Matemática nesta etapa de ensino, buscando conhecer as fragilidades da disciplina, bem como oferecendo recursos para a melhoria da qualidade do ensino de Matemática nas escolas. 


\section{REFERÊNCIAS}

AGUIAR, Eliane Vigneron Barreto; FLÔRES, Maria Lúcia Pozzatti. Objetos de Aprendizagem: conceitos básicos. In: TAROUCO, Liane Margarida Rockenbach. et al (Org.). Objetos de Aprendizagem: teoria e prática. Porto Alegre: Evangraf, 2014.

AZEVEDO, Italândia Ferreira de; SILVA, Monaliza de Azevedo; ALVES, Francisco Régis Vieira. Objetos de Aprendizagem que abordam o pensamento algébrico nos anos iniciais: uma proposta para o ensino de sequências e padrões. Revista de Estudos e Pesquisas sobre Ensino Tecnológico, v. 6, Edição Especial Desafios e Avanços Educacionais em Tempos da COVID-19, 2020.

BARBOSA, Ana; BORRALHO, António; BARBOSA, Elsa; CABRITA, Isabel; VALE, Isabel; FONSECA, Lina. Padrões em Matemática: Uma proposta didática no âmbito do novo programa para o Ensino Básico. Lisboa: Texto Editores, 201 .

BOUCHERVILLE, Gisele Cristina de; VIANA, Adriana Bachx Noronha. Modelagem de situações de uso didático em ensino tecnológico. Educitec, Manaus, v. 5, n. II, p. 37-54, jun., 2019. Disponível em: https://doi.org/ro.31417/educitec.v5irı.686. Acesso em: Io nov. 2020.

BRASIL. Ministério da Educação. Base Nacional Comum Curricular (BNCC). Brasília: MEC. 2018.

http://basenacionalcomum.mec.gov.br/images/BNCC_EI_EF_IIO518_versaofinal_ site.pdf. Acesso em: 20 mar. 2019.

CARNEIRO, Maria Lúcia Fernandes; SILVEIRA, Milene Selbach. Objetos de Aprendizagem como elementos facilitadores na Educação a Distância. Educar em Revista, Curitiba, Edição Especial, n. 4, p. 235-260, 2014. Disponível em: https://doi.org/10.1590/o104-4060.38662. Acesso em or nov. 2020.

CASTRO FILHO, José Aires de. Objetos de aprendizagem e sua utilização no ensino de matemática. In: Encontro Nacional de Educação Matemática, 9, 2007, Belo Horizonte MG. Anais... Belo Horizonte (MG): Sociedade Brasileira de Educação Matemática, 2007, p. I-I5. Disponível em: http://paginapessoal.utfpr.edu.br/kalinke/grupos-depesquisa/pde/pdf/objetos_de_aprendizagem_e_EM.pdf. Acesso em: or nov. 2020.

CAZELLA, Sílvio César; SILVA, Ketia Kellen; BHEAR, Patrícia; SCHNEIDER, Daisy; FREITAS, Rodrigo. Recomendando Objetos de Aprendizagem com base em competências em EAD. Revista Renote, v. 9, n. 2, p. I-Io, 20II. Disponível em: https://doi.org/10.22456/1679-1916.25123. Acesso em: 10 nov. 2020.

COSTA, João Francisco Staffa da; LIMA, Valderez Marina do Rosário; VASCONCELOS, Emanuella Silveira; DEBUS, Adriano Rodrigo. Uso dos softwares de autoria na elaboração de recursos didáticos para a formação de professores. Revista Eletrônica de Educação, v. I4, p. I-I7, 2020. Disponível em: https://doi.org/Io.14244/198271993750. Acesso em or nov. 2020. 
GIL, Antônio Carlos. Como elaborar projetos de pesquisa. 4. ed. São Paulo: Atlas, 2002.

HANAUER, Eny Santos Oliveira. Ludicidade na aprendizagem em tempos de pandemia. Revista Ibero-Americana de Humanidades, Ciências e Educação- REASE, v. 6, n. II, p. I6II67, 2020. Disponível em: https://periodicorease.pro.br/rease/article/view/245. Acesso em: Io abr. 202I.

JUNGBLUTH, Adriana; SILVEIRA, Everaldo; GRANDO, Regina Célia. O estudo de sequências na Educação Algébrica nos Anos Iniciais do Ensino Fundamental. Educação Matemática Pesquisa, São Paulo, v. 2I, n. 3, p. 96-II8, 2019. Disponível em: https://doi.org/I0.23925/1983-3156.2019vol21i3p96-II8. Acesso em io nov. 2020.

OLIVEIRA, Willians Adriano. Ensino de sequências: dos parâmetros curriculares nacionais à base nacional comum curricular. Anais ... XXIII Encontro Brasileiro de Estudantes de Pós-Graduação em Educação Matemática, UNICSUL - Campus Anália Franco, São Paulo - SP, 25 a 27 de outubro de 2019.

PONTE, João Pedro da.; BRANCO, Neusa; MATOS, Ana. Álgebra no ensino básico. Lisboa: ME, Direção Geral de Inovação e de Desenvolvimento Curricular, 2009.

RAMOS, Fábio Mendes. Objeto de Aprendizagem - Ensino de Sistemas de Equações Lineares aplicados em circuitos. Revista Ibero-Americana de Humanidades, Ciências e Educação- REASE, v. 7, n. 2, p. 296-308, fev. 2021. Disponível em: https://doi.org/I0.5189I/rease.v7i2.598. Acesso em: 10 abr. 2021.

SANTANA, Camila Lima Santana e; SALES, Kathia Marise Borges. Aula em casa: Educação, Tecnologias digitais e Pandemia COVID-ı. Interfaces Científicas, Aracaju, v. io, n. I, p. 75-92, 2020. Disponível em: 10.17564/2316-3828.2020vionip75-92. Acesso em: 23 out. 2020.

SCOLARI, Angélica Taschetto; BERNARDI, Giliane; CORDENONSI, Andre Zanki. O desenvolvimento do Raciocínio Lógico através de Objetos de Aprendizagem. Revista Renote, v. 5, n. 2, p. I-IO, 2007. Disponível em: https://seer.ufrgs.br/renote/article/view/I4253/8169. Acesso em: 23 out. 2020. 